\title{
An overview of exposure parameters, dose measurements and strategies for dose reduction in pediatric CT examinations
}

\author{
P. Akhlaghi, H. Miri Hakimabad and L. Rafat Motavalli ${ }^{\mathrm{a}}$ \\ Physics department, School of Sciences, Ferdowsi University of Mashhad, 91775-1436 Mashhad, Iran.
}

Received 23 December 2012 - Accepted 29 April 2013

\begin{abstract}
CT scanning technology is a valuable tool to diagnose many diseases; however, the level of the radiation dose is a source of concern, especially for children. CT scan systems and dose measurement methods have evolved over the years; but reported pediatric effective doses (EDs) have sometimes exceeded the annual dose limit recommended by the ICRP ( $1 \mathrm{mSv}$ per year for persons under 18 years) (ICRP, 2007a). Efforts have been made to reduce organ doses and EDs by adjusting the scan parameters. This paper describes the determinants of the ED, and the dose reduction techniques in pediatric imaging from the early age of CT examinations until now. The first epidemiological results regarding the associated risk of cancer are also briefly presented.
\end{abstract}

Keywords: pediatric CT scan / effective dose / scan parameters / dose reduction

\section{Introduction}

Since its introduction in 1973, CT has established itself as a valuable diagnostic imaging modality. More than 1000 CT scanners were in use in 50 countries in 1979 (Friedland and Thurber, 1996), a 10\% annual growth in the global CT market was reported in the year 2002 (ICRP, 2007a), and currently 6,000 scanners are in use in the United States (Medicine Health, 2012). According to surveys conducted at US medical facilities, the annual number of CT examinations increased from approximately 3.6 million in 1980 to 33 million in 1998 (Nickoloff and Alderson, 2001), and now this value is over 70 million (Brenner, 2010). Currently, the proportion of pediatric patients undergoing CT scans ranges from 0 to $38 \%$ depending on the country and examination type (Muhogora et al., 2010).

CT examinations contribute 40 to $67 \%$ of the collective dose (UNSCEAR report, Annex D, 2000). This imaging procedure delivers about $67 \%$ of the overall radiation dose to the pediatric population (Mettler et al., 2000). Crude estimations showed that the ED ranges between $6 \mathrm{mSv}$ and $100 \mathrm{mSv}$ for pediatric patients (Brenner, 2002).

$\mathrm{CT}$ is a major source of medical radiation and its availability and frequency of scanning is responsible for increasing the dose from CT practice. Due to the high ED of CT, an effort to minimize it is critically important. This is especially important in children, because the younger the patient is at the time of exposure to radiation, the greater the risk (BEIR VII Phase 2, 2005). Due to the higher radiosensitivity of children's cells, the

\footnotetext{
a rafat@ferdowsi.um.ac.ir
}

lifetime cancer risk associated with an individual CT examination is higher in children than in adults (ICRP, 2007a) and there is an increased risk for thyroid, skin, brain and breast cancer in children (UNSCEAR report, Annex I, 2000). In addition, due to children's longer lifetime to manifest radiation-induced cancer, and the fact that cancer risk is cumulative over a lifetime, radiation risk from $\mathrm{CT}$ in children is one of the major current concerns in CT dosimetry (Frush et al., 2003).

Over the years, CT technology has evolved, with various impacts on the radiation dose. After the introduction of conventional CT, helical CT became commercially available in the USA and it was on the market in 1991 (Zeman et al., 1998). Because of its new advantages, the use of CT imaging increased in the pediatric population. Although helical technology provides additional opportunities for CT in children, the radiation dose associated with helical CT is much greater than the dose associated with most other imaging procedures (Donnelly et al., 2001).

Concerns about the radiation dose to children increased with multi-detector row CT (MDCT) introduced in the late 1990s (Donnelly et al., 2000). This is because multi-slices are acquired in each gantry rotation. Relative to CT scanners from the early 1990s, MDCT scanners result in doses that are $\sim 1.7$ higher per unit mAs in body phantoms (Huda and Vance, 2007).

In addition, until 2001, children and adults were scanned with identical protocols, which did not differentiate between the large differences in patient sizes (Paterson et al., 2001; Brody et al., 2007). Since there is great variability in body size in the pediatric population, adjusting CT scan parameters such as tube current and voltage is necessary. As reported, 
the ED to children from CT examinations increases as body size decreases if the exposure factors are kept constant (Caon et al., 2000). Pediatric protocols should therefore have lower tube current and voltage than those for adults. If spatial resolution is not an issue, the lower tube current settings should be selected as much as possible (Frush and Donnelly, 1998).

The results of the Society for Pediatric Radiologists survey indicated that radiologists now paid more attention to sizebased adjustments (Hollingsworth, 2003). If CT parameters used for children are not adjusted based on examination type, or age or size of the child, then some patients will be exposed to an unnecessarily high radiation dose during CT imaging (Donnelly et al., 2001; Khursheed et al., 2002; Pages et al., 2003). Colang et al. (2007) declared that if settings were adjusted based on neonate weight, the dose to the brain (head CT) and stomach (abdominal CT) would be 2 and 4 times smaller than that of unadjusted settings, respectively. Recently, in a cohort study in Britain, it was estimated that in children CT, delivering cumulative doses of about $50 \mathrm{mGy}$ and $60 \mathrm{mGy}$ might almost triple the risk of leukemia and brain tumors, respectively (Pearce et al., 2012). According to the importance of pediatric CT dosimetry, the aim of this paper is to review the main parameters influencing doses received by children, the associated risk and some dose reduction methods.

\section{Quantifying the pediatric dose from CT}

Radiation doses in CT (organ dose and ED) are estimated in two different ways, by experimental procedures and computer simulations. Two additional dose quantities, the weighted $\mathrm{CT}$ dose index $\left(\mathrm{CTDI}_{\mathrm{w}}\right)$ in $\mathrm{mGy}$ for a single slice and dose length product (DLP) in mGy.cm per complete examination, which are measured in the CTDI phantoms (homogeneous cylinders of PMMA, with diameters of 16 or $32 \mathrm{~cm}$ ), give information about relative changes in dose (Shrimpton and Wall, 2000).

\subsection{Experimental procedures}

This section includes dose determination in clinical procedures or experimental measurements with physical phantoms which are scanned by the CT machine to determine dose distributions within the human body. Some of these physical phantoms use simple shapes (rectangular and cylindrical) to display human anatomy (Liu et al., 1996) but they are often made of a human skeleton with tissue-equivalent material simulating the soft tissues and are constructed as vertical slices with small holes for dosimeter placement. Pediatric organ dose calculation started with determining the surface and internal radiation doses in abdominal CT (Brasch et al., 1978; Brasch and Cann 1982). Later, the surface dose was compared with CTDI data to estimate the entrance exposures to a set of ATOM phantoms (a family of physical phantoms manufactured by CIRS which include head, torso, upper femur and genitalia) in chest and abdomen-pelvis (AP) CT (Cody et al., 2004). Commonly, the CT dose is represented by the ED and organ absorbed doses. In Table 1, some studies that investigated the pediatric received dose by clinical procedures or physical measurements are tabulated.

In addition to the dose, the diagnostic reference level (DRL) is specified to promote optimization of patient protection. Shrimpton and Wall (2000) calculated the third quartile of the $\mathrm{CTDI}_{\mathrm{w}}$ and DLP as the DRL, in brain, chest, abdomen and pelvis scans for a baby to a 15 -year-old child, which were 20 $70 \mathrm{mGy}$ and 50-800 mGy.cm, separately. Later, in a national survey, they determined UK DRL for pediatric head and chest scans. They reported that the CTDI ${ }_{w}$ and DLP ranged from 15 to $56 \mathrm{mGy}$ and 76 to $508 \mathrm{mGy} . \mathrm{cm}$, respectively (Shrimpton et al., 2006).

\subsection{Monte Carlo simulation}

Computer simulation for dose estimation is the most reliable way to obtain accurate values of organ doses under CT imaging (Lee et al., 2011). Some Monte Carlo (MC) programs using MCNPX (Khursheed et al., 2002; Lee et al., 2007; Gu et al., 2009; Lee et al., 2012) and PENELOPE (Li et al., 2011) were developed which simulate the dose inside the computational models of the human body.

Using MC in pediatric CT started with determination of the organ dose per air kerma for head and chest scans with single detector CT (SDCT) at tube voltages of 80 and $125 \mathrm{kV}$ for GSF phantoms (BABY and CHILD). The maximum organ doses per air kerma in chest scans were in the breast ( 0.96 for BABY and 0.88 for CHILD) (Zankl et al., 1995). Some studies only investigated the amount of the dose absorbed in one organ. In head and neck CT examinations, the mean dose to the thyroid was calculated using stylized phantoms representing 1 year to 15 years old. The thyroid dose varied between 0.6-8.7 mGy and 15.2-52.0 mGy in head and neck CT imaging, respectively (Mazonakis et al., 2007).

In a retrospective cohort study of over 240000 children in UK and by using an organ dose database from MC simulation, Kim et al. (2012) reported the absorbed dose in the brain, thyroid, breast and RBM of a newborn to a 22-year-old in head, chest and abdomen scans before and after 2001. The maximum dose of the brain, thyroid, breast and RBM before (after) 2001 were 56 (44.2), 27.7 (13), 36.9 (13.3) and 17.1 (8.6) mGy, respectively. The EDs calculated in some studies by MC methods are given in Table 2.

\section{CT dose reduction methods}

Improvements in CT technology (e.g. detector efficiency, geometry efficiency, current modulation and reconstruction algorithms) have decreased patient doses significantly. Starting in the 1990s, significant efforts have been made to lower the dose to the pediatric population (ICRP, 2000). By changing the CT parameters based on the patient's weight or age, the dose is reduced significantly. However, the radiation dose should only be reduced under the condition that the diagnostic image quality is not sacrificed to ensure appropriate diagnosis. 
Table 1. Studies that calculated the dose by physical measurements or clinical procedures.

\begin{tabular}{|c|c|c|c|c|c|c|c|c|c|c|}
\hline \multirow{2}{*}{ Reference } & \multicolumn{5}{|c|}{ ED in $\mathrm{mSv}$ (mean organ dose in mGy) } & \multirow{2}{*}{ CT scanner } & \multicolumn{2}{|c|}{ CT parameters } & \multirow{2}{*}{ Dosimeter } & \multirow{2}{*}{ Subject under exposure } \\
\hline & Head & Chest & Abdomen & $\mathrm{AP}$ & Trunk & & Tube voltage in $\mathrm{kVp}$ & Tube loading in $\mathrm{mAs}$ & & \\
\hline $\begin{array}{l}\text { Fearon and Vucich, } \\
1987\end{array}$ & $(0.02-5.3)$ & $(0.2-14.8)$ & $(0.08-3.22)$ & - & $(0.32-16)$ & GE CT/T 9800 & 120 & 280 & TID & $\begin{array}{c}\text { 6-y-old phantom } \\
\text { (Humanoid System, CA) }\end{array}$ \\
\hline $\begin{array}{l}\text { Axelsson et al., } \\
\qquad 1996\end{array}$ & $\begin{array}{c}\sim 2 \\
(0.05-37)\end{array}$ & - & - & - & $\begin{array}{l}\sim 10 \\
(0.4-17)\end{array}$ & GE HiSpeed Advantage & 120 & 200 and 340 & TID & $\begin{array}{c}\text { 1-y-old phantom } \\
\text { (manufactured by CIRS) }\end{array}$ \\
\hline $\begin{array}{l}\text { Ware et al., } \\
\qquad 1999\end{array}$ & - & - & $4.4-7.5$ & - & - & GE HiSpeed Advantage & 120 & $220-290$ & - & $\begin{array}{c}63 \text { patients } \\
\text { (under } 18 \text { years) }\end{array}$ \\
\hline $\begin{array}{l}\text { Lucaya et al., } \\
\qquad 2000\end{array}$ & - & $1.1-7$ & - & - & - & CT Twin II-Plus & 120 & 34,50 and 180 & - & $\begin{array}{c}25 \text { patients } \\
\text { (under } 19 \text { years) }\end{array}$ \\
\hline $\begin{array}{l}\text { Papadimitriou et al., } \\
\qquad 2000\end{array}$ & $1.3-2.68$ & $2.83-5.11$ & $9.11-12.12$ & - & - & Philips Tomoscan LX Serial & 100 and 120 & $\begin{array}{l}142,237,190, \\
\text { and } 362\end{array}$ & TID, IC ${ }^{a}$ & $\begin{array}{l}3 \text { cylindrical and } 1 \text { elliptical } \\
\text { PMMA phantoms }\end{array}$ \\
\hline $\begin{array}{l}\text { Huda et al., } \\
\qquad 2000\end{array}$ & - & $\begin{array}{l}6.4(50 \mathrm{~kg})- \\
9.6(10 \mathrm{~kg})\end{array}$ & - & - & - & GE Hi-Speed CT/i & 120 & 250 and 260 & - & $\begin{array}{l}44 \text { pediatric patients (under } \\
18 \text { years) with weights } 10-50 \mathrm{~kg}\end{array}$ \\
\hline $\begin{array}{l}\text { Huda et al., } \\
\quad 2001\end{array}$ & $4.5-10.7$ & - & - & - & - & GE Hi-Speed CT/i & 120 & $198-344$ & - & $\begin{array}{l}23 \text { infants (average age of } 9 \text { months } \\
\text { and average weight of } 5.9 \mathrm{~kg} \text { ) }\end{array}$ \\
\hline $\begin{array}{l}\text { Pages et al., } \\
\quad 2003\end{array}$ & $0.4-2.3$ & $1.1-6.6$ & $2.3-19.9$ & - & - & $5 \mathrm{SDCT}$ and $2 \mathrm{MDCT}$ scanners & $\begin{array}{l}120,137 \\
\text { and } 140\end{array}$ & $18.8-300$ & $\mathrm{IC}^{\mathrm{a}}$ & $\begin{array}{l}\text { PMMA phantom for pediatric } \\
\text { patients (1-, 5- and 10-y-old) }\end{array}$ \\
\hline $\begin{array}{l}\text { Moss and McLean, } \\
2006\end{array}$ & $1.34-2.34$ & $1.91-7.94$ & $4.73-14.14$ & - & - & $\begin{array}{l}\text { Helical CT scanners } \\
\text { (SDCT and MDCT) }\end{array}$ & $114.29-124.71$ & $16.27-226.21$ & - & $\begin{array}{l}\text { 8-week-old and 5- to 7-y-old } \\
\text { pediatric patients }\end{array}$ \\
\hline $\begin{array}{l}\text { Galanski et al., } \\
2006\end{array}$ & $1.8-2.4$ & $1.6-3.7$ & $2.9-7.9$ & - & - & $\begin{array}{l}\text { MDCT and SDCT scanners of } \\
\text { Siemens, Philips, Toshiba and GE }\end{array}$ & $100-128$ & $44-327$ & - & $\begin{array}{l}\text { Pediatric patients } \\
\text { (under } 15 \text { years) }\end{array}$ \\
\hline $\begin{array}{l}\text { Rybka et al., } \\
\quad 2007\end{array}$ & $\begin{array}{c}0.2(0.1-7.7) \\
0.7(0.3-29.9)\end{array}$ & - & - & - & - & SDCT scanner PQ-2000 (Picker) & $\begin{array}{l}100 \\
120\end{array}$ & $\begin{array}{l}150 \\
225\end{array}$ & $\mathrm{LiF}$ (TLD) & $\begin{array}{l}\text { Rando Man phantom } \\
\text { (Alderson, USA) }\end{array}$ \\
\hline $\begin{array}{l}\text { Fujii et al., } \\
\quad 2007\end{array}$ & - & $\begin{array}{l}1.3-7.4 \\
(2-21)^{\mathrm{b}}\end{array}$ & $\begin{array}{l}2.8-10.5 \\
(3-16)^{\mathrm{b}}\end{array}$ & - & - & $\begin{array}{c}\text { MDCT scanners }(8,16 \text { and } 64 \\
\text { detectors) }\end{array}$ & 120 & $40-160$ & photodiodes & $\begin{array}{c}\text { 6-y-old phantom } \\
\text { (manufactured by Kyoto Kagaku) }\end{array}$ \\
\hline $\begin{array}{l}\text { Donadieu et al., } \\
\quad 2007\end{array}$ & - & $\begin{array}{c}1.5-29.3 \\
(2.7-18.6)^{\mathrm{b}}\end{array}$ & - & - & - & $\begin{array}{l}\text { GE Light Speed Ultra and } \\
\text { Siemens Somatom Plus } 4\end{array}$ & $\begin{array}{l}100,120 \\
\text { and } 140\end{array}$ & $30-300$ & - & $\begin{array}{l}65 \text { pediatric patients (under } \\
15 \text { years) with cystic fibrosis }\end{array}$ \\
\hline $\begin{array}{l}\text { Nishizawa et al., } \\
2008\end{array}$ & $\begin{array}{c}2.6 \\
(18-80)^{\mathrm{b}}\end{array}$ & $\begin{array}{c}1.67-8.17 \\
(4.78-24.5)^{\mathrm{b}}\end{array}$ & - & - & - & $\begin{array}{l}6 \text { types of MDCT scanners } \\
\quad(4 \text { and } 16 \text { detectors })\end{array}$ & 120 & $\begin{array}{c}25-160 \\
\text { (for chest) }\end{array}$ & TID & $\begin{array}{c}\text { 6-y-old phantom } \\
\text { (manufactured by Kyoto Kagaku) }\end{array}$ \\
\hline $\begin{array}{c}\text { Fahey, } \\
2009\end{array}$ & - & - & - & - & $\begin{array}{l}9.24-12.41 \\
(5.4-15.95)\end{array}$ & Discovery LS; GE Healthcare & 120 & 100 & $\mathrm{IC}^{\mathrm{a}}$ & $\begin{array}{l}4 \text { phantoms simulating the torso of } \\
\text { newborn, 1-, 5- and 10-y-old }\end{array}$ \\
\hline $\begin{array}{l}\text { Kim et al., } \\
2010\end{array}$ & - & - & $\begin{array}{l}8.1(0-1.6)^{\mathrm{c}} \\
\text { and } 37.8(0-7.2)\end{array}$ & - & - & Cone beam $\mathrm{CT}$ scanner & 125 & 1340 & MOSFETs & $\begin{array}{l}\text { 5-y-old phantom } \\
\text { (ATOM 705-D, CIRS) }\end{array}$ \\
\hline $\begin{array}{l}\text { Fujii et al., } \\
\quad 2011\end{array}$ & $\begin{array}{l}2.3-2.4 \\
(28-36)^{\mathrm{b}}\end{array}$ & $\begin{array}{l}1.7-6.7 \\
(3-11)^{\mathrm{b}}\end{array}$ & - & $\begin{array}{l}3.6-7.8 \\
(5-11)^{\mathrm{b}}\end{array}$ & - & 2 types of 64 MDCT scanners & 120 & $13-200$ & RGD $^{d}$ & $\begin{array}{c}\text { 1-y-old child } \\
\text { (ATOM Model 704-C, CIRS) }\end{array}$ \\
\hline $\begin{array}{l}\text { Bernier } \text { et al., } \\
\quad 2012\end{array}$ & $\begin{array}{c}0.85(0.4-50) \\
1.4(1-73)\end{array}$ & $\begin{array}{c}3.05(0.1-31) \\
2.2(1-18)\end{array}$ & - & $\begin{array}{l}9.55(4-33) \\
6.15(3-28)\end{array}$ & - & $\begin{array}{l}10 \text { SDCT scanners } \\
12 \text { MDCT scanners }\end{array}$ & - & - & - & $\begin{array}{l}27362 \text { pediatric patients undergoing } \\
\text { CT at } 14 \text { radiology departments }\end{array}$ \\
\hline
\end{tabular}

a Pencil ion chamber.

b Mean absorbed dose for organs within the scanning area.

c Values are related to two different protocols.

${ }^{\mathrm{d}}$ Radiophotoluminescence glass detector.

\subsection{Tube voltage adjustment}

The tube voltage determines the energy distribution of the X-ray beam, so many authors have investigated the effect of tube voltage variation on changing the CT dose. Reid et al. (2010) determined the effect of tube voltage reduction on three cylindrical phantoms of an infant, child and adolescent based on the patient circumference to optimize dose reduction for abdominal CT with no change in image quality. Doses increased by the power function of $\mathrm{kVp}^{n}$ for increases in $\mathrm{kVp}$ with $n$ being between 2.49 and 3.12.

Because of image noise and beam-hardening artifacts (which appear as nonuniformities in the CT numbers), sometimes the trend to decrease tube voltage (and correspondingly, the radiation dose) was not successful (Cody et al., 2004; Nakayama et al., 2005). So, tube voltage reduction is allowed only on the condition that it does not affect the ability to detect low-visibility structures. By reducing the X-ray tube potential from $120 \mathrm{kVp}$ to $80 \mathrm{kVp}$ at $160 \mathrm{~mA}$, the value of the $\mathrm{CT}$ dose index of a 10-year-old phantom decreased about 67\% (Fahey, 2009). Using $80 \mathrm{kVp}$ instead of $120 \mathrm{kVp}$ lowered the dose to the patient by approximately $30 \%$ (Siegel, 2003; Yekeler, 2004). A reduction in dose of about $78 \%$ in a circular phantom was obtained by Siegel et al. (2004) by decreasing the tube voltage from $140 \mathrm{kVp}$ to $80 \mathrm{kVp}$ (at $165 \mathrm{mAs}$ ).

\subsection{Tube current reduction}

Adjustments in the tube current are more frequently used to improve management of the radiation dose for children. The survey of Hollingsworth et al. (2003) showed a trend to increase tube current with increasing age. In 1999, tube current reduction from the default setting of 200-250 mAs to 125-150 mAs resulted in a $40 \%$ reduction in the radiation dose to children (Chan et al., 1999). Another study (Lucaya et al., 2000) shows that a dose reduction of $72 \%$ and $80 \%$ could be obtained when the standard $180 \mathrm{mAs}$ was decreased to 50 and 
Table 2. Studies that calculated the dose by MC.

\begin{tabular}{|c|c|c|c|c|c|c|c|c|c|c|}
\hline \multirow[b]{2}{*}{ Reference } & \multirow[b]{2}{*}{ Head } & \multicolumn{3}{|c|}{$\mathrm{ED}$ in $\mathrm{mSv}$ (mean organ dose in $\mathrm{mGy}$ ) } & \multirow[b]{2}{*}{ Trunk } & \multirow[b]{2}{*}{ CT scanner } & \multicolumn{2}{|c|}{ CT parameters } & \multirow[b]{2}{*}{ Phantom } & \multirow[b]{2}{*}{ Comments } \\
\hline & & Chest & Abdomen & $\mathrm{AP}$ & & & $\begin{array}{l}\text { Tube voltage } \\
\text { in } k V_{p}\end{array}$ & $\begin{array}{l}\text { Tube loading } \\
\text { in mAs }\end{array}$ & & \\
\hline $\begin{array}{l}\text { Huda et al., } \\
\quad 1997\end{array}$ & $1.5-6$ & - & $3.1-5.3$ & - & - & GE HiSpeed Advantage & 120 & $150-400$ & $\begin{array}{l}\text { Cylindrical water } \\
\text { equivalent phantoms }\end{array}$ & EGS4 \\
\hline $\begin{array}{l}\text { Caon et al., } \\
2000\end{array}$ & - & $2.6-2.8$ & $2.3-2.5$ & - & $7.8-9$ & GE HiSpeed Advantage & 120 & 100 & $\begin{array}{l}3 \text { voxel models of } 12,14 \\
\text { (ADELAIDE) and } 16 \text { years old }\end{array}$ & EGS4 \\
\hline $\begin{array}{l}\text { Khursheed et al., } \\
\qquad 2002\end{array}$ & - & $\begin{array}{c}6.3-7.8 \\
8.8-17.1 \\
11.1-15.8\end{array}$ & - & - & - & $\begin{array}{l}\text { Siemens DRH } \\
\text { GE } 9800 \\
\text { Philips LX }\end{array}$ & 120 and 125 & $\begin{array}{c}230,320, \\
\text { and } 330\end{array}$ & $\begin{array}{l}5 \text { stylized phantoms from newborn } \\
\text { to } 15 \text { years (developed by Cristy } \\
\text { and Eckerman) with some changes }\end{array}$ & MCNP \\
\hline $\begin{array}{l}\text { McLean et al., } \\
\qquad 2003\end{array}$ & - & $\begin{array}{l}6.33 \\
6.09\end{array}$ & $\begin{array}{l}8.16 \\
6.88\end{array}$ & - & - & $\begin{array}{l}\text { SDCT and MDCT } \\
\text { (4 detectors) }\end{array}$ & 120 & $140,150,170$, and 230 & $\begin{array}{l}\text { 7-y-old child } \\
\text { 8-week-old baby }\end{array}$ & $\begin{array}{c}\text { Investigation in } 9 \text { radiology } \\
\text { departments by dose } \\
\text { calculation software (CTEXPO) }\end{array}$ \\
\hline $\begin{array}{l}\text { Huda and Vance, } \\
\qquad 2007\end{array}$ & $\begin{array}{l}0.9-3.6 \\
(30-40)\end{array}$ & $\begin{array}{l}1.5-4 \\
(7-18)\end{array}$ & $\begin{array}{c}2-3 \\
(7-15)\end{array}$ & - & - & GE HiSpeed Advantage & 120 & $40-280$ & $\begin{array}{l}\text { Uniform cylinders of water } \\
\text { modeling head, chest and abdomen }\end{array}$ & MC dosimetry data \\
\hline $\begin{array}{l}\text { Lee } \text { et al., } \\
\qquad 2007\end{array}$ & $\begin{array}{l}0.61-1.36 \\
(0-20.14)^{\mathrm{a}}\end{array}$ & $\begin{array}{l}3.79-5.7 \\
(0-14.97)^{\mathrm{a}}\end{array}$ & $\begin{array}{c}2.81-5.56 \\
(0.01-14.35)^{\mathrm{a}}\end{array}$ & $\begin{array}{c}6.05-9.97 \\
(0.01-17.39)^{\mathrm{a}}\end{array}$ & $\begin{array}{c}10.92-14.21 \\
(0.08-18.71)^{\mathrm{a}}\end{array}$ & $\begin{array}{l}\text { SOMATOM Sensation } \\
16 \text { helical MDCT }\end{array}$ & 80,100 , and 120 & 100 & $\begin{array}{l}\text { Ten pediatric phantoms, } 5 \text { stylized } \\
\text { (ORNL) and } 5 \text { tomographic (UF voxel) }\end{array}$ & MCNPX2.5. \\
\hline $\begin{array}{l}\text { Lee } \text { et al., } \\
\qquad 2012\end{array}$ & $\begin{array}{c}0.6-1.3 \\
(0-15.9)^{\mathrm{b}}\end{array}$ & $\begin{array}{c}4.6-9.9 \\
(0-17.9)^{\mathrm{b}}\end{array}$ & - & $\begin{array}{l}6.3-11.4 \\
(0-17.5)^{\mathrm{b}}\end{array}$ & $\begin{array}{l}8.8-14.5 \\
(0-18.3)^{\mathrm{b}}\end{array}$ & $\begin{array}{l}\text { SOMATOM Sensation } \\
16 \text { helical MDCT }\end{array}$ & 80,100 and 120 & 100 & $\begin{array}{l}\text { Pediatric hybrid phantoms } \\
\text { (developed at University of } \\
\text { Florida and National Cancer Institute) }\end{array}$ & MCNPX2.6. \\
\hline
\end{tabular}

a At tube voltage of $120 \mathrm{kVp}$ and based on ICRP Publication 60 (ICRP, 1990) weighting factors.

b At tube voltage of $120 \mathrm{kVp}$ and based on ICRP Publication 103 (ICRP, 2007b) weighting factors.

34 mAs, respectively. In 2003, dose reduction factors were determined for head and abdominal MDCT in children. Using the reduction factors, pediatric doses were reduced to about $23 \%$ and decreased the number of fatal cancers per year by 384 (from 500 to 116) (Boone et al., 2003). The effect of lower tube current on structure detection was investigated in pediatric CT. Frush et al. (2002) found that lowering the current to $67 \%$ of the tube current of the original abdominal MDCT scan did not affect the ability to detect high-visibility structures. Even tube current reductions of 33-50\% were acceptable for detection of low-visibility structures. Li et al. (2008) indicated that with $75 \%$ current reduction, there is no general statistically significant difference in diagnostic accuracy, and the radiation dose decreased by up to $75 \%$. Currently, automatic tube current modulation (ATCM) is a new technique for radiation dose management (Paterson and Frush, 2007; Coursey et al., 2008).

\subsection{The optimum level of tube current and voltage}

There are some rules to optimize doses in pediatric CT scans with no loss of diagnostic ability (Vock, 2005). In a study of 30 abdominal helical CT scans of children aged 3 months to 7 years, the optimum level of tube current at a tube voltage of $100 \mathrm{kVp}$ was investigated. It was declared that, most anatomical structures in children were demonstrated at low tube current, and just for imaging a few anatomic structures with small details, performing a CT scan at higher $\mathrm{mA}$ would be useful (Wormanns et al., 2001). Using three CTDI phantoms simulating the abdomen of an infant, child and adolescent, Reid et al. (2010) optimized abdominal CT procedures; adjusting $\mathrm{mAs}$ and $\mathrm{kVp}$ depending on the abdominal circumference.

The results of a recent survey conducted in 2008 showed changes in pediatric body MDCT scanning parameters. Now, $98 \%$ of radiologists use either a weight-based or an age-based protocol for pediatric CT. The average tube current has decreased to between 31 and $61 \mathrm{~mA}$ for all age ranges. All radiologists now use a peak kilovoltage of $120 \mathrm{kVp}$ or less for routine pediatric chest and abdominal CT (Arch and Frush, 2008).

According to the results of another survey in 2012, using pediatric-specific adjustments a newborn received a lower absorbed dose in the thyroid, breast and brain than an adult male in a chest and brain scan, respectively (Kim et al., 2012).

\subsection{Adjusting the pitch}

With the advent of helical CT, scanning techniques became more sophisticated. In addition to tube current and voltage, pitch is a selectable parameter (Paterson et al., 2001) which can be increased while tube current decreases (Donnelly et al., 2001; Karabulut and Ariyürek, 2006). For pediatric SDCT, pitches of 1.5 or greater have been recommended for general body scanning (Hollingsworth et al., 2003). By increasing the pitch from 1.0 to 1.5, Paterson et al. (2001) decreased the radiation dose by $33 \%$.

\subsection{Shielding of superficial organs}

Radiation dose reduction using organ shields was started in the early 2000s. Fricke et al. (2003) studied the amount of dose reduction by using a bismuth breast shield for MDCT of the chest and abdomen in female pediatric patients. The results indicated the shield enabled a $6.7 \%$ decrease in the radiation dose to the lungs and a $29 \%$ decrease to the breast with no appreciable loss in diagnostic quality. Coursey et al. (2008) assessed the effect of bismuth breast shields on the radiation dose during pediatric chest 16-MDCT. Using this shield with a 
tube current of $65 \mathrm{~mA}$, the breast dose was reduced by $26 \%$. In 2007, orbit dose was measured during pediatric cranial MDCT with and without bismuth shielding. The average dose reduction to eyes thanks to bismuth shielding was $42 \%$ at $120 \mathrm{kVp}$ (Mukundan et al., 2007). In 2011, eye and thyroid doses were assessed using a bismuth shield in Slovakia. The best reduction in the eye dose due to the use of bismuth shields was within the range of 56-65\% and for the thyroid it was $25 \%$. Using an eye shield, some artifacts were observed but the decrease in image quality was not unsatisfactory (Gbelcova et al., 2011).

\section{The cancer risk associated with $\mathrm{CT}$ radiation}

The principal long-term disadvantage of CT is the radiation exposure. It should be noted that the risk of cancer increases linearly with increasing dose until extensive cell killing takes place at very high exposures. The cancer risk depends on both sex and age, with higher risks for females and for those exposed at younger ages. A strong decrease in risk was observed with increasing age (BEIR VII Phase 2, 2005).

Some authors assessed lifetime cancer risks attributable to the exposure in pediatric CT from the value of the received dose (Brenner et al., 2001; Galanski et al., 2006; Paterson and Frush, 2007; Iakovou et al., 2008). Recently, in an epidemiological study, the excess risk of leukemia and brain tumors (with Poisson relative risk models) after CT scans of patients without previous cancer diagnoses who were younger than 22 years were assessed. They declared that for head, chest and abdomen CT compared with doses of less than $5 \mathrm{mGy}$, the relative risk of leukemia for patients who received a cumulative dose of at least $30 \mathrm{mGy}$ was 3.18 and the relative risk of brain cancer for patients who received a cumulative dose of 50-74 mGy was 2.82 (Pearce et al., 2012).

\section{Discussion and conclusions}

The IAEA survey shows that use of CT in the 2-year interval from 2007 to 2009 has increased and the lowest frequency of pediatric CT examinations was in European facilities $(4.3 \%)$. The highest frequency of CT in children was reported in Asia (9.4\% in 2007 and 12.2\% in 2009) and in Africa (9.6\% in 2007 and $7.8 \%$ in 2009). The results show that although the total number of CT examinations in children has increased globally, the recommendations on imaging are not always followed in some developing countries (Vassileva et al., 2012).

Although databases for organ doses and EDs in pediatric CT examinations were developed primarily in the 1990s, there is still a critical need to update these values. Moreover, all the studies focused on dose estimation for pediatric reference models, and according to the dependence of the radiation dose on the shape and size of the body, the amount of the dose in non-reference anatomies would be vital. Therefore, the use of NURBS-based hybrid phantoms can help in modeling non-reference subjects and improving the patient-specific dose estimates. Such a vast range of databases can provide more accurate estimation of cancer risk and patient-specific reporting of organ doses due to CT imaging (Xu and Eckerman, 2010).

Although CT scanners have been improved and dose reduction techniques have been introduced, in some countries, exposure of children remains a concern. There is, therefore, a strong need to implement guidelines in pediatric CT examinations and use of alternative examinations. It is in parallel also critical to follow populations of exposed children in welldesigned epidemiological studies.

\section{References}

Arch M.E., Frush D.P. (2008) Pediatric body MDCT: a 5-Year followup survey of scanning parameters used by pediatric radiologists, Am. J. Roentgenol. 191, 611-617.

Axelsson B., Persliden J., Schuwert P. (1996) Dosimetry for computed tomography examination of children, Radiat. Prot. Dosim. 64, 221-226.

BEIR VII Phase 2 (2005) Health risks from exposure to low levels of ionizing radiation, The national academies press, 1-423.

Bernier M.O. et al. (2012) Radiation exposure from CT in early childhood: a French large-scale multicentre study, Brit. J. Radiol. 85, 53-60.

Boone J.M., Geraghty E.M., Seibert J.A., Wootton-Gorges S.L. (2003) Dose reduction in pediatric CT: a rational approach, Radiology 228, 352-360.

Brasch R.C., Boyd D.P., Gooding C.A. (1978) Computer tomographic scanning in children: comparison of radiation dose and resolving power of commercial CT scanners, Am. J. Roentgenol. 131, 95101.

Brasch R.C., Cann C.E. (1982) Computer tomographic scanning in children: II an updated comparison of radiation dose and resolving power of commercial CT scanners, Am. J. Roentgenol. 138, 127-133.

Brenner D.J. (2002) Estimating cancer risks from pediatric CT: going from the qualitative to the quantitative, Pediatr. Radiol. 32, 228231.

Brenner D.J. (2010) Slowing the increase in the population dose resulting from CT scans, Radiat. Meas. 174, 809-815.

Brenner D.J., Elliston C.D., Hall E.J., Berdon W.E. (2001) Estimated risks of radiation- induced fatal cancer from pediatric CT, Am. J. Roentgenol. 176, 289-296.

Brody A.S., Frush D.P., Huda W., Brent R.L. (2007) Radiation risk to children from computed tomography, Pediatrics 120, 677-682.

Caon M., Bibbo G., Pattison J. (2000) Monte Carlo calculated effective dose to teenage girls from computed tomography examinations, Radiat. Prot. Dosim. 90, 445-448.

Chan C., Wong Y., Chau L., Yu S., Lau P. (1999) Radiation dose reduction in pediatric cranial CT, Pediatr. Radiol. 29, 770-775.

Cody D.D., Moxley D.M., Krugh K.T., O'Daniel J.C., Wagner L.K., Eftekhari F. (2004) Strategies for formulating appropriate MDCT techniques when imaging the chest, abdomen, and pelvis in pediatric patients, Am. J. Roentgenol. 182, 849-859.

Colang J.E., Killion J.B., Vano E. (2007) Patient dose from CT: a literature review, Radiologic Technology 79, 17-26.

Coursey C., Frush D.P., Yoshizumi T., Toncheva G., Nguyen G., Greenberg S.B. (2008) Pediatric chest MDCT using tube current modulation: effect on radiation dose with breast shielding, Am. J. Roentgenol. 190, 54-61. 
Donadieu J., Roudier C., Saguintaah M., Maccia C., Chiron R (2007) Estimation of the radiation dose from thoracic CT scans in a cystic fibrosis population, CHEST 132, 1233-1238.

Donnelly L.F., Frush D.P., Nelson R.C. (2000) Multislice helical CT to facilitate combined $\mathrm{CT}$ of the neck, chest, abdomen, and pelvis in children, Am. J. Roentgenol. 174, 1620-1622.

Donnelly L.F. et al. (2001) Minimizing radiation dose for pediatric body applications of single-detector helical CT: strategies at a large children's hospital, Am. J. Roentgenol. 176, 303-306.

Fahey F.H. (2009) Dosimetry of Pediatric PET/CT, J. Nucl. Med. 50, 1483-1491.

Fearon T., Vucich J. (1987) Normalized pediatric organ - absorbed doses from CT examinations, Am. J. Roentgenol. 148, 171-174.

Fricke B.L. et al. (2003) In-plane bismuth breast shields for pediatric $\mathrm{CT}$ : effects on radiation dose and image quality using experimental and clinical data, Am. J. Roentgenol. 180, 407-411.

Friedland G.W., Thurber B.D. (1996) The birth of CT, Am. J. Roentgenol. 167, 1365-1370.

Frush D.P., Donnelly L.F. (1998) Helical CT in children: technical consideration and body applications, Radiology 209, 37-48.

Frush D.P. et al. (2002) Computer-simulated radiation dose reduction for abdominal multidetector CT of pediatric patients, Am. J. Roentgenol. 179, 1107-1113.

Frush D.P., Donnelly L.F., Rosen N.S. (2003) Computed tomography and radiation risks: what pediatric health care providers should know, Pediatrics 112, 951-957.

Fujii K., Aoyama T., Koyama S., Kawaura C. (2007) Comparative evaluation of organ and effective doses for pediatric patients with those for adults in chest and abdominal CT examinations, Brit. J. Radiol. 80, 657-667.

Fujii K. et al. (2011) Evaluation of organ doses in CT examinations with an infant anthropomorphic phantom, Radiat. Prot. Dosim. 147, 151-155.

Galanski M., Nagel H.D., Stamm G. (2006) Pediatric CT exposure practice in the federal republic of Germany, http://www. mh-hannover.de/fileadmin/kliniken/diagnostische_radiologie/ download/Report_German_Paed-CTSurvey_2005_06.pdf.

Gbelcova L., Nikodemova D., Horvathova M. (2011) Dose reduction using bismuth shielding during pediatric CT examinations in Slovakia, Radiat. Prot. Dosim. 147, 160-163.

Gu J., Bednarz B., Caracappa P.F., Xu X.G. (2009) The development, validation and application of a multi-detector CT (MDCT) scanner model for assessing organ doses to the pregnant patient and the fetus using Monte Carlo simulations, Phys. Med. Biol. 54, 2699-2717.

Hollingsworth C., Frush D.P., Cross M., Lucaya J. (2003) Helical CT of the body: a survey of techniques used for pediatric patients, Am. J. Roentgenol. 180, 401-406.

Huda W., Atherton J.V., Ware D.E., Cumming W.A. (1997) An approach for the estimation of effective radiation dose at CT in pediatric patients, Radiology 203, 417-422.

Huda W., Scalzetti E.M., Roskopf M. (2000) Effective doses to patients undergoing thoracic computed tomography examinations, Med. Phys. 27, 838-844.

Huda W., Chamberlain C.C., Rosenbaum A.E. (2001) Radiation doses to infants and adults undergoing head CT examinations, Med. Phys. 28, 393-399.

Huda W., Vance A. (2007) Patient radiation doses from adult and pediatric CT, Am. J. Roentgenol. 188, 540-546.

Iakovou I., Karavida N., Kotzassarlidou M. (2008) The computerized tomography scans and their dosimetric safety, Hell. J. Nucl. Med. 11, 82-85.
ICRP Publication 60 (1990) Recommendations of the International Commission on Radiological Protection, Pergamon, 1-204.

ICRP Publication 87 (2000) Managing patient dose in computed tomography, Pergamon, 1-45.

ICRP Publication 102 (2007a) Managing patient dose in multidetector computed tomography (MDCT), Pergamon, 1-79.

ICRP Publication 103 (2007b) The 2007 Recommendations of the International Commission on Radiological Protection, Pergamon, $1-328$.

Karabulut N., Ariyürek M. (2006) Low dose CT: practices and strategies of radiologists in university hospitals, Diagn. Interv. Radiol. 12, 3-8.

Khursheed A., Hillier M.C., Shrimpton P.C., Wall B.F. (2002) Influence of patient age on normalized effective doses calculated for CT examinations, Brit. J. Radiol. 75, 819-830.

Kim S., Yoshizumi T.T., Frush D.P., Toncheva G., Yin F. (2010) Radiation dose from cone beam CT in a pediatric phantom: risk estimation of cancer incidence, Am. J. Roentgenol. 194, 186-190.

Kim K.P. et al. (2012) Development of a database of organ doses for pediatric and young adult CT scans in the United Kingdom, Radiat. Prot. Dosim. 150, 415-426.

Lee C. et al. (2007) Organ and effective doses in pediatric patients undergoing helical multislice computed tomography examination, Med. Phys. 34, 1858-1873.

Lee C. et al. (2011) Organ doses for reference adult male and female undergoing computed tomography estimated by Monte Carlo simulations, Med. Phys. 38, 1196-1206.

Lee C., Kim K.P., Long D.J., Bolch W.E. (2012) Organ doses for reference pediatric and adolescent patients undergoing computed tomography estimated by Monte Carlo simulation, Med. Phys. 39, 2129-2146.

Li X., Samei E., DeLong D.M., Jones R.P, Colsher J.G., Frush D.P. (2008) Towards assessing the diagnostic influence of dose reduction in pediatric CT: a study based on simulated lung nodules. In: Proceedings of SPIE conference on the physics of medical imaging, February 16-21, SanDiego, conf. 6913, 6913L16913L12.

Li X. et al. (2011) Patient-specific radiation dose and cancer risk estimation in CT: Part I. Development and validation of a Monte Carlo program, Med. Phys. 38, 397-407.

Liu A., Williams L.E., Raubitschek A.A. (1996) A CT assisted method for absolute quantitation of internal radioactivity, Med. Phys. 23, 1919-1928.

Lucaya J., Piqueras J., García-Peña P., Enríquez G., García-Macías M., Sotil J. (2000) Low-dose high-resolution CT of the chest in children and young adults: dose, cooperation, artifact incidence, and image quality, Am. J. Roentgenol. 175, 985-992.

Mazonakis M., Tzedakis A., Damilakis J., Gourtsoyiannis N. (2007) Thyroid dose from common head and neck CT examinations in children: is there an excess risk for thyroid cancer induction? Eur. Radiol. 17, 1352-1357.

McLean D., Malitz N., Lewis S. (2003), Survey of effective dose levels from typical pediatric CT protocols, Australasian Radiology 47, 135-142.

Medicine health (2012) http://www.emedicinehealth.com/ct_scan/ article_em.htm.

Mettler F.A. Jr, Wiest P.W., Locken J.A., Kelsey C.A. (2000) CT scanning: patterns of use and dose, J. Radiol. Prot. 20, 353-359.

Moss M., McLean D. (2006) Pediatric and adult computed tomography practice and patient dose in Australia, Australasian Radiology 50, 33-40.

Muhogora W.E. et al. (2010) Pediatric CT examinations in 19 developing countries: frequency and radiation dose, Radiat. Prot. Dosim. 140, 49-58. 
Mukundan S. Jr, Wang P.I., Frush D.P., Yoshizumi T., Marcus J., Kloeblen E., Moore M. (2007) MOSFET dosimetry for radiation dose assessment of bismuth shielding of the eye in children, $A m$. J. Roentgenol. 188, 1648-1650.

Nakayama Y. et al. (2005) Abdominal CT with low tube voltage: preliminary observations about radiation dose, contrast enhancement, image quality, and noise, Radiology 237, 945-951.

Nickoloff E.L., Alderson P.O. (2001) Radiation exposures to patients from CT: reality, public perception, and policy, Am. J. Roentgenol. 177, 285-287.

Nishizawa K. et al. (2008) Patient dose estimation for multi-detectorrow CT examinations, Radiat. Prot. Dosim. 128, 98-105.

Pages J., Buls N., Osteaux M. (2003) CT doses in children: a multicentre study, Brit. J. Radiol. 76, 803-811.

Papadimitriou D., Louizi A., Makri T., Theodoropoulos B., Proukakis C. (2000) Computed tomography dosimetry in children, Radiat. Prot. Dosim. 90, 417-422.

Paterson A., Frush D.P., Donnelly L.F. (2001) Helical CT of the body: are settings adjusted for pediatric patients? Am. J. Roentgenol. 176, 297-301.

Paterson A., Frush D.P. (2007) Dose reduction in pediatric MDCT: general principles, Clin. Radiol. 62, 507-517.

Pearce M.S. et al. (2012) Radiation exposure from CT scans in childhood and subsequent risk of leukemia and brain tumors: a retrospective cohort study, LANCET 380, 499-505.

Reid J., Gamberoni J., Dong F., Davros W. (2010) Optimization of $\mathrm{kVp}$ and $\mathrm{mAs}$ for pediatric low-dose simulated abdominal CT: is it best to base parameter selection on object circumference? Am. J. Roentgenol. 195, 1015-1020.

Rybka K., Staniszewska M.A., Biegañski T. (2007) Low-dose protocol for head CT in monitoring hydrocephalus in children, Med. Sci. Monit. 13, 147-151.

Shrimpton P.C., Wall B.F. (2000) Reference doses for pediatric computed tomography, Radiat. Prot. Dosim. 90, 249-252.

Shrimpton P.C., Hillier M.C., Lewis M.A., Dunn M. (2006) National survey of doses from CT in the UK: 2003, Brit. J. Radiol. 79, 968-980.
Siegel M.J. (2003) Multiplanar and three-dimensional multi-detector row $\mathrm{CT}$ of thoracic vessels and airways in the pediatric population, Radiology 229, 641-650.

Siegel M.J., Schmidt B., Bradley D., Suess C., Hildebolt C. (2004) Radiation dose and image quality in pediatric CT: effect of technical factors and phantom size and shape, Radiology 233, 515522.

UNSCEAR 2000, Annex D, United Nations scientific committee on the effects of atomic radiation report to the general assembly (2000) Medical Radiation Exposures, New York.

UNSCEAR 2000, Annex I, United Nations scientific committee on the effects of atomic radiation report to the general assembly (2000) Epidemiological evaluation of radiation-induced cancer, New York.

Vassileva J. et al. (2012) IAEA survey of pediatric CT practice in 40 countries in Asia, Europe, Latin America, and Africa: Part 1, frequency and appropriateness, Am. J. Roentgenol. 198, 10211031.

Vock P. (2005) CT dose reduction in children, Eur. Radiol. 15, 23302340.

Ware D.E., Huda W., Mergo P.J., Litwiller A.L. (1999) Radiation effective doses to patients undergoing abdominal CT examinations, Radiology 210, 645-650.

Wormanns D. et al. (2001) Abdominal spiral CT in children: which radiation exposure is required? Eur. Radiol. 11, 2262-2266.

Xu X.G., Eckerman K.F. (2010) Applications to computed tomography for pediatric patients. In: Handbook of anatomical models for radiation dosimetry, pp. 487-510. Taylor \& Francis, New York.

Yekeler E. (2004) Pediatric abdominal applications of multidetectorrow CT, Eur. J. Radiol. 52, 31-43.

Zankl M., Panzer W., Petoussi N., Drexler G. (1995) Organ doses for children from computed tomographic examinations, Radiat. Prot. Dosim. 57, 393-396.

Zeman R.K., Baron R.L., Jeffery R.B. Jr, Klein J., Siegel M.J., Silverman P.M. (1998) Helical body CT: evolution of scanning protocols, Am. J. Roentgenol. 170, 1427-1438.

Cite this article as: P. Akhlaghi, H. Miri Hakimabad, L. Rafat Motavalli. An overview of exposure parameters, dose measurements and strategies for dose reduction in pediatric CT examinations, Radioprotection 49(1), 9-15 (2014). 